\title{
Teses de Doutorado
}

Defendidas em 2006.1 no Programa de Pós-Graduação em Psicologia Clínica - PUC-Rio

Vergonha: a revelação da catástrofe narcísica - para uma compreensão da clínica contemporânea

No ventre da cadeia: um estudo sobre os projetos futuros de mulheres encarceradas

A cidade como um texto: fragmentos da experiência homossexual masculina no Rio de Janeiro contemporâneo

De broto a flor. Um estudo sobre a construção de projetos de vida por adolescentes fluminenses

A transitoriedade: uma nova leitura

Um real em jogo: a função do pai e o sujeito na clínica

As contribuições de D. W. Winnicott para a compreensão da psicossomática: um estudo sobre as alergias respiratórias na primeira infância 


\title{
VERGONHA: A REVELAÇÃO DA CATÁSTROFE NARCÍSICA - PARA UMA COMPREENSÃO \\ DA CLÍNICA CONTEMPORÂNEA
}

\author{
Cid Merlino Fernandes
}

A histeria foi usada como modelo para expressar uma forma de sofrimento psíquico típica do final do século XIX. Esta tese se propõe justificar que a melancolia é o quadro mais adequado para traduzir a forma de padecimento psíquico atual. Para demonstração da pertinência desta proposta, o afeto da vergonha é destacado e analisado. O problema narcísico articulado ao desenvolvimento deste afeto e sua particularidade na melancolia são mencionados como pontos de aproximação com os ruídos clínicos atuais e com uma forma própria do homem de hoje lidar com a idéia de não se bastar e precisar do outro.

\section{BANCA:}

Ana Maria Rudge (Orientadora)

Junia de Vilhena

Manoel Tosta Berlinck

Maria Teresa da Silveira Pinheiro

Silvia Maria Abu-Jamra Zornig

Data de defesa: 27/01/2006 


\section{NO VENTRE DA CADEIA: UM ESTUDO SOBRE OS PROJETOS FUTUROS DE MULHERES ENCARCERADAS}

Neilza Alves Barreto

O objetivo do trabalho é investigar a existência ou não de projetos futuros em mulheres encarceradas. Partindo do pressuposto de que as instituiçôes totais têm como característica principal a desubjetivação do sujeito, buscou-se analisar a fala de 154 presas em suas singularidades. A maternidade e a família apresentaram-se como temas na fala da grande maioria das entrevistadas. Religião, beleza e trabalho foram também categorias que, muitas vezes, surgiram como linhas de fuga, face ao duro cotidiano prisional.

\section{BANCA:}

Junia de Vilhena (Orientadora) Magda Diniz Bezerra Dimenstein

Maria Helena Rodrigues Navas Zamora

Maria Inês G. F. Bittencourt

Marilene Rosa Nogueira da Silva

Data de defesa: 31/01/2006 


\title{
A CIDADE COMO UM TEXTO: FRAGMENTOS DA EXPERIÊNCIA HOMOSSEXUAL MASCULINA NO RIO DE JANEIRO CONTEMPORÂNEO
}

\author{
Marcelo Santana Ferreira
}

O presente trabalho é uma reflexão acerca da experiência homossexual masculina contemporânea, estudada a partir da proposição de dezenove imagens de sociabilidades construídas no texto da cidade por homens que se relacionam com homens. Apóia-se essencialmente nos estudos de Walter Benjamin sobre a modernidade européia e nos originais trabalhos de Michel Foucault sobre a emergência de uma ciência da sexualidade moderna.

\section{BANCA:}

Solange Jobim e Souza (Orientadora)

Carlos Augusto Peixoto Junior

Heliana de Barros Conde Rodrigues

Luis Antônio dos Santos Baptista

Monique Rose Aimée Augras

Data de defesa: 03/02/2006 
DE BROTO A FLOR. UM ESTUDO SOBRE A CONSTRUÇÃO DE PROJETOS DE VIDA POR ADOLESCENTES FLUMINENSES

Cintia Miranda Scelza

A tese discute as referências culturais mobilizadas por adolescentes de duas cidades do estado do Rio de Janeiro na elaboração de seus projetos de vida. Utilizou-se uma metodologia sócio-histórica e entrevistas individuais com adolescentes, que foram posteriormente analisadas com o método de análise de conteúdo. Observou-se que há indicadores, no discurso dos sujeitos, de baixa tolerância com relação às relações de autoridade e de um olhar predominantemente subjetivo para o mundo, bem como para as escolhas que este proporciona.

\section{BANCA:}

Bernardo Jablonski (Orientador)

Helena Amaral da Fontoura

Lucia Rabello de Castro

Solange Jobim e Souza

Terezinha Féres-Carneiro

Data de defesa: 09/02/2006 


\title{
A TRANSITORIEDADE: UMA NOVA LEITURA
}

\author{
José Otávio de Vasconcellos Naves
}

O texto de Freud intitulado "Sobre a transitoriedade" (1916 [1915]) ganha uma nova leitura que permite rediscutir a noção de consciência e suas relações com a percepção e o desenvolvimento do eu. $\mathrm{Na}$ sua transitoriedade, a consciência valoriza o caráter passageiro do estímulo, gerando a concentração da iluminação. Este caminho lhe é imposto tanto pelo desejo inconsciente quanto pela percepção. Nas neuroses narcísicas, o enrijecimento da transitoriedade da consciência assume formas distintas, tornando o estabelecimento da transferência um trabalho de difícil construção. A possibilidade de pensar o tratamento levando em consideração a transitoriedade da consciência em suas relaçôes com a cultura abre perspectivas para o re-entendimento da clínica psicanalítica.

\section{BANCA:}

Terezinha Féres-Carneiro (Orientadora)

Antônio Carlos de Sá Earp

Jurandir Sebastião Freire Costa

Monique Rose Aimée Augras

Nelson Ernesto Coelho Junior

Data de defesa: 10/02/2006 


\section{UM REAL EM JOGO: A FUNÇÃO DO PAI E O SUJEITO NA CLÍNICA}

Paula Mancini Cordeiro de Mello Ribeiro

Parte-se de um trabalho de atendimento psicanalítico a crianças, adolescentes e autores de agressão em situações de violência doméstica, que se insere em um contexto atual de declínio da função paterna. A complexidade dessa função do pai é trabalhada a partir de Freud e, principalmente, com Lacan. A partir da leitura estrutural de Lacan da questão paterna, com as noções de significante, Nome do Pai e dos três registros do real, simbólico e imaginário situa-se a diferença que se coloca na clínica psicanalítica quando não se reduz a complexidade em jogo na função do pai para o sujeito.

\section{BANCA:}

Marcus André Vieira (Orientador)

Ana Maria Rudge

Antônio Márcio Ribeiro Teixeira

Anna Carolina Lo Bianco Clementino

Francisco Leonel de Figueiredo Fernandes

Data de defesa: 17/02/2006 


\section{As CONTRIBUIÇÕES DE D. W. WinNICOTT PARA A COMPREENSÃO DA PSICOSSOMÁTICA: UM ESTUDO SOBRE AS ALERGIAS RESPIRATÓRIAS NA PRIMEIRA INFÂNCIA}

Ramilda Fontan Soto

O objetivo da tese é contribuir para a compreensão das manifestações psicossomáticas na infância, exemplificadas por meio dos distúrbios alérgicos respiratórios. A teoria de Winnicott sobre o desenvolvimento emocional primitivo foi utilizada como principal ferramenta teórica. Foram discutidas as contribuiçôes dos autores identificados com a psicossomática psicanalítica, desde o modelo teórico de Pierre Marty até a literatura relativa a infância, e também os conceitos de Winnicott sobre a relação mãe-bebê. Utilizou-se o conceito winnicottiano de preocupação materna primária, com foco na adaptação ativa materna, revelandose a existência de uma relação entre as falhas adaptativas maternas e a manifestação psicossomática alérgica da criança.

\section{BANCA:}

Claudia Amorim Garcia (Orientadora)

Flavia Sollero de Campos

Marco Antônio Chagas Guimarães

Maria Stella Tavares Filgueiras

Monah Winograd

Data de defesa: 20/02/2006 